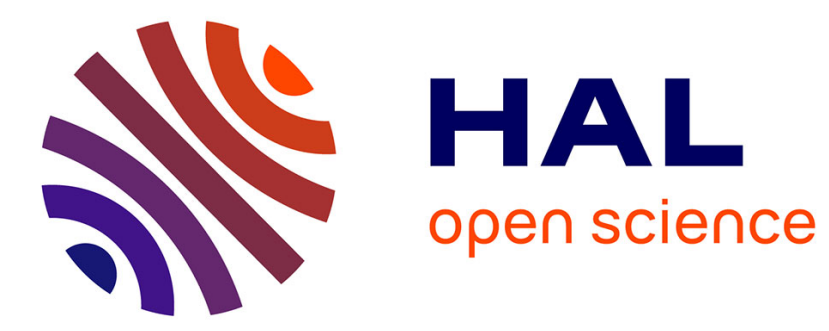

\title{
Development of Melilite-Type Oxide Ion Conductors
}

\author{
Lijia Zhou, Jungu Xu, Mathieu Allix, Xiaojun Kuang
}

\section{To cite this version:}

Lijia Zhou, Jungu Xu, Mathieu Allix, Xiaojun Kuang. Development of Melilite-Type Oxide Ion Conductors. Chemical Record, 2020, 20 (10), pp.1117-1128. 10.1002/tcr.202000069 . hal-03089510

\section{HAL Id: hal-03089510 https://hal.science/hal-03089510}

Submitted on 28 Dec 2020

HAL is a multi-disciplinary open access archive for the deposit and dissemination of scientific research documents, whether they are published or not. The documents may come from teaching and research institutions in France or abroad, or from public or private research centers.
L'archive ouverte pluridisciplinaire HAL, est destinée au dépôt et à la diffusion de documents scientifiques de niveau recherche, publiés ou non, émanant des établissements d'enseignement et de recherche français ou étrangers, des laboratoires publics ou privés. 


\title{
Development of Melilite-Type Oxide Ion Conductors
}

\author{
Lijia Zhou, ${ }^{[a]}$ Jungu Xu, ${ }^{[a]}$ Mathieu Allix, ${ }^{[b]}$ and Xiaojun Kuang, ${ }^{*[a, c]}$
}

\begin{abstract}
Lowering the operating temperature of solid oxide fuel cells (SOFCs) requires high performance oxide ion conductor electrolytes. Recently tetrahedra-based structures have been attracting considerable attention for oxide ion conductor development, among which the layered tetrahedral network melilite structure appears particularly interesting owing to its remarkable capability to accommodate and transport interstitial oxide ions, compared with isolated tetrahedral anion structures. Stabilization and migration mechanisms of interstitial oxide ions in melilites have been systematically investigated using local structural relaxation from both electrostatic Coulomb interaction and chemical bonding aspects based on atomic and electronic structures respectively using experimental and theoretical approaches. These reveal cationic size and chemical bonding effects on stabilization and migration mechanisms of interstitial oxide ions. Lately, full crystallization from glass, an innovative synthesis method, was employed to produce new metastable melilite oxide ion conductors which are inaccessible using classic solid state reaction owing to cationic size effect. Finally, the thermal and chemical stability at low temperature and the high oxide ion conductivity of the best melilite oxide ion conductors based on $\mathrm{LaSrGa}_{3} \mathrm{O}_{7}$ are likely to provide real possibilities of applications of melilite-type electrolytes in SOFCs and other related devices.
\end{abstract}

Keywords: Melilite, oxide ion conductors, defect structure, tetrahedron, solid oxide fuel cells

\section{Introduction}

Melilite materials generally refer to alkali and alkaline earth silicates, aluminosilicate minerals or solid solutions with the general formula $\mathrm{A}_{2} \mathrm{~B}^{\prime}\left(\mathrm{B}_{2} \mathrm{O}_{7}\right)$ featuring a layered tetrahedral network structure, where $A$ is an alkali metal or alkaline earth metal cation, $\mathrm{B}^{\prime}$ is $\mathrm{Mg}, \mathrm{Fe}, \mathrm{Co}$ etc., and $\mathrm{B}$ is $\mathrm{Si}$ or $\mathrm{Al}$. The tetrahedral layers of the melilite structure are composed of corner-sharing $\mathrm{B}_{2} \mathrm{O}_{7}$ tetrahedral dimers which are connected with $\mathrm{B}^{\prime}$ ions in four directions to form $\mathrm{B}^{\prime}\left(\mathrm{B}_{2} \mathrm{O}_{7}\right)$ tetrahedral layers with fived-fold tunnels (Figure 1a). These tetrahedral layers are bound together by large $\mathrm{A}$ cations to form alternating $\mathrm{A}_{2}$ layers and $\mathrm{B}^{\prime}\left(\mathrm{B}_{2} \mathrm{O}_{7}\right)$ tetrahedral layers. The large $\mathrm{A}$ cations are eight-coordinated and located in the five-fold tunnels, and the tetrahedral layers above and below the A cation provide four oxygens each to coordinate with $A$ cation (Figure $1 \mathrm{~b}$ ). In the $\mathrm{B}^{\prime}\left(\mathrm{B}_{2} \mathrm{O}_{7}\right)$ tetrahedral layer, all oxygen atoms of $\mathrm{B}^{\prime} \mathrm{O}_{4}$

(a)

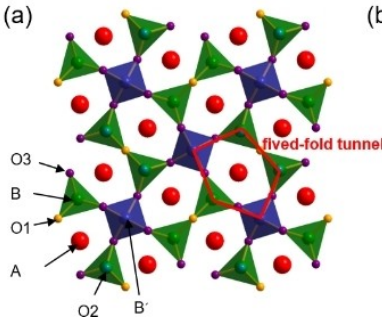

(b)

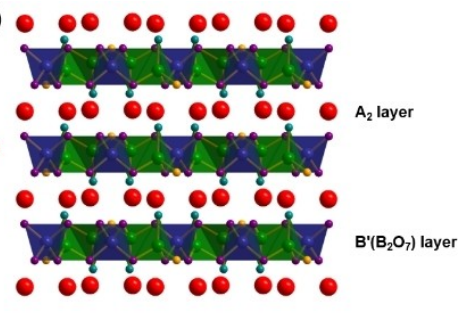

Figure 1. The crystal structure of $\mathrm{A}_{2} \mathrm{~B}^{\prime}\left(\mathrm{B}_{2} \mathrm{O}_{7}\right)$ melilite projected along (a) [001] and (b) [010] directions. 
tetrahedra are bridging atoms, while the tetrahedron in $\mathrm{B}_{2} \mathrm{O}_{7}$ dimers has three bridging oxygens and one terminal oxygen. This connection of the tetrahedra is called $(3,4)$-connection (the number three and four denote that there are two kinds of tetrahedra with three and four bridging oxygen atoms in the structure, respectively). The common base members for the natural melilite mineral solid solution are $\mathrm{Ca}_{2} \mathrm{MgSi}_{2} \mathrm{O}_{7}$ (kermanite) $^{[1]}$ and $\mathrm{Ca}_{2} \mathrm{Al}(\mathrm{AlSi}) \mathrm{O}_{7}$ (gehlenite) $^{[2]}$. In addition to natural silicate and aluminosilicate minerals, the melilite family contains a large and growing number of

artificially prepared germanates, gallates and aluminates, among which the gallate melilite compounds containing rare earth elements and alkali metal elements are the most common.

$\mathrm{LaSrGa}_{3} \mathrm{O}_{7}$ is a typical gallate melilite which was often observed as a secondary phase in the synthesis of the wellknown $\mathrm{Sr}$, Mg-doped perovskite $\mathrm{LaGaO}_{3}$ (LSGM) electrolyte by solid state reaction. ${ }^{[3]}$ Steins et al. ${ }^{[4]}$ successfully prepared a $\mathrm{LaSrGa}_{3} \mathrm{O}_{7}$ single crystal by Czochralski method and analyzed its structure, which was found to belong to the tetragonal melilite structure in space group with the lattice parameters $a=8.056 \AA$ and $c=5.333 \AA$. The structure consists of alternating $\mathrm{Ga}_{3} \mathrm{O}_{7}$ tetrahedral layers and cationic $(\mathrm{La} / \mathrm{Sr})_{2}$ layer

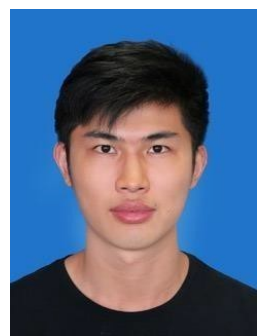

Lijia Zhou received her BS degree in College of Materials Science and Engineering from Jingdezhen Ceramic Institute in 2016. He pursued his master degree and joined the research group of Inorganic Materials and Solid Chemistry under supervision of Prof. Xiaojun Kang. Currently, his research interests mainly focus on synthesis of ion conductor materials.

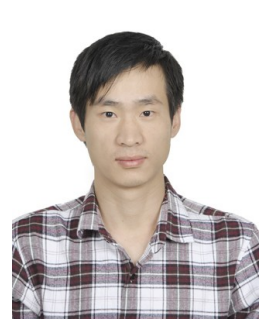

Jungu $\mathrm{Xu}$ is an associated professor In Guilin University of Technology. He received his Ph.D degree from Sun YatSen University. Dr. Xu's research mainly focuses on structure and electrical property characterization of materials for solid oxide fuel cell electrolytes (both oxide ion and proton conducting oxides) and electrodes. along the $c$ axis. The $\mathrm{La}$ and $\mathrm{Sr}$ cations randomly occupy the same crystallographic position in the fived-fold tunnels. The stoichiometric $\mathrm{LaSrGa}_{3} \mathrm{O}_{7}$ material is an insulator. In 2004, Rozeumek et al. ${ }^{[5-7]}$ investigated the phase diagram of $\mathrm{La}_{2} \mathrm{O}_{3}-\mathrm{SrO}-\mathrm{Ga}_{2} \mathrm{O}_{3}$ ternary system and found that the $\mathrm{La} / \mathrm{Sr}$ ratio is tunable in the lanthanum gallate melilite structure, i.e. $\mathrm{La}$ and $\mathrm{Sr}$ cations can substitute for each other to form a $\mathrm{La}_{1+}$ ${ }_{x} \mathrm{Sr}_{1-x} \mathrm{Ga}_{3} \mathrm{O}_{7+\delta}$ solid solution. This solid solution limit in air at $1470{ }^{\circ} \mathrm{C}$ can extend from $x=-0.2$ to $x=0.6$. Remarkably, when $x=0.45$, the oxide ion conductivity reaches $-0.1 \mathrm{~S} / \mathrm{cm}$ at $950^{\circ} \mathrm{C}$. Based on neutron powder diffraction, Rozeumek et al. ${ }^{[6,7]}$ considered that the existence of a certain amount of oxygen vacancies in the materials is the main reason for its high conductivity. On the contrary, in 2005, Raj et al. reported that a single-phase melilite material can be obtained only in the range of $x<0.05$, and its oxide ion conductivity only reached $-10^{-3} \mathrm{~S} / \mathrm{cm}$ at $950^{\circ} \mathrm{C} .{ }^{[8]}$ In 2008 , Kuang et al. ${ }^{[9]}$ made a systematic and in-depth investigation of the $\mathrm{La}_{1+x} \mathrm{Sr}_{1-}$ ${ }_{x} \mathrm{Ga}_{3} \mathrm{O}_{7+\delta}$ system on the preparation, conductivity and structure. A single melilite phase with high oxide ion conductivity $\left(0.02-0.1 \mathrm{~S} / \mathrm{cm}\right.$ over the $600-900{ }^{\circ} \mathrm{C}$ temperature range) was obtained for the La-rich composition $\mathrm{La}_{1.54} \mathrm{Sr}_{0.46} \mathrm{Ga}_{3} \mathrm{O}_{7.27}$, the best melilite oxide ion conductor so

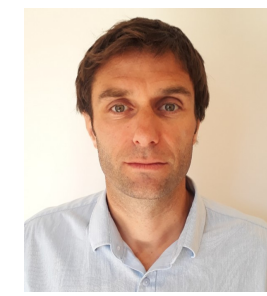

Mathieu Allix received his $\mathrm{PhD}$ degree from the University of Caen, France, in 2004. After a postdoctoral trainning at the University of Liverpool, he joined the CNRS at the CEMHTI lab in Orléans, France in 2006. His current research interests include (i) the crystallization processes in oxide glasses with an application to the elaboration of new transparent (glass-)ceramics and (ii) the synthesis and structure determination of new inorganic materials.

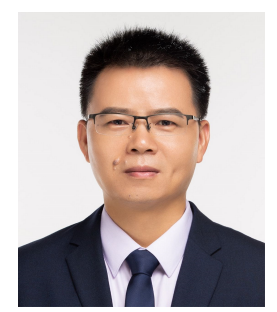

Xiaojun Kuang received B.Sc degree in Chemistry at Nanchang University in 1999 and Ph.D. degree in Inorganic Chemistry at Peking University in 2004. After postdoctoral trainning in University of Liverpool and University of Durham, he was appointed as an associate professor in Chemistry College, Sun Yat-Sen University in 2010 before he settled down in Guilin in 2013. His current research interests include discovery of new oxide ion conductors, oxide and (oxy)nitride dielectrics and their structure-property relationship. 
far. The charge carriers for the oxide ion migration in this material were identified as interstitial oxygen defects by using Rietveld refinement from neutron powder diffraction (NPD) data. Through a finely structural analysis via separating the bulk and defect structures using a site-split model on variable temperature NPD data, the mechanisms of stabilization and migration of interstitial oxide defects were well elucidated. ${ }^{[9]}$

The charge carrier type of oxide ion migration in crystalline materials is either interstitial oxygen or oxygen vacancies. The large majority of materials are vacancy-mediated oxide ion conductors; while interstitial oxide ion conductors are relatively scarce. Due to the flexibility of rotation and deformation of isolated tetrahedra, interstitial oxide ion conductors were mainly found in isolated tetrahedral anion structures, such as $\mathrm{La}_{10-x}\left(\mathrm{MO}_{4}\right)_{6} \mathrm{O}_{3-1.5 x}(\mathrm{M}=\mathrm{Si}, \mathrm{Ge})$ apatite-type silicate $^{[10-12]}$ and germanate materials. ${ }^{[13]}$ Corner-shared tetrahedra possess reduced rotation and deformation flexibility. Therefore, oxide ion conductors with a connected tetrahedral network structure are less observed. The earliest oxide ion conductivity observed in a 3-dimensional (3D) tetrahedral network was initially reported in 1988 on $\mathrm{Ca}_{12} \mathrm{Al}_{14} \mathrm{O}_{33}$ mayenite, in which the oxygen atoms isolated from $\mathrm{AlO}_{4}$ tetrahedra and clatherated in the subnanometer-sized cages formed by tetrahedral framework atoms and Ca cations display relatively low mobility. ${ }^{[14,15]}$ Melilite is the second example of oxide ion conductors based on a linked tetrahedral network structure. Its oxide ion conductivity is higher than that of traditional fluorite-type Y-stabilized zirconia (YSZ) electrolytes (0.03-0.13 S/cm over the $800-1000^{\circ} \mathrm{C}$ temperature range), ${ }^{[16]}$ and essentially equivalent to that of Gd-doped cerium (GDC) oxide material $\left(0.046 \mathrm{~S} / \mathrm{cm} \text { at the } 700^{\circ} \mathrm{C} \text { temperature) }\right)^{[17]} \mathrm{The}$ identification of interstitial oxide ion conduction in $\mathrm{La}_{1+x} \mathrm{Sr}_{1-}$ ${ }_{x} \mathrm{Ga}_{3} \mathrm{O}_{7+0.5 x}$ melilite has attracted considerable attention since $2008 .^{[18-22]}$

The discovery of interstitial oxide ion conduction in the melilite structure and its original mechanism for the interstitial oxide ion conduction have offered new clues to search for innovative oxide ion conductors. These developments have thus stimulated the exploration of new melilite interstitial oxide ion conductors and in-depth understanding of their interstitial oxygen migration mechanisms. They also triggered the exploration of oxide ion conductors in other tetrahedrabased structures sharing similar structural features. In this review, we summarize the progress on preparation of new melilite-type oxide ion conductors, and also present experimental and theoretical studies on the defect stabilization and migration mechanisms in the melilite family since 2008 and give a perspective on the possible discovery of future oxide-ion conductors based on the structures containing tetrahedral moieties.

\section{Stabilization of Interstitial Oxide Ions}

\subsection{Defect Structure in $\mathrm{La}_{1.54} \mathrm{Sr}_{0.46} \mathrm{Ga}_{3} \mathrm{O}_{7.27}$ From Diffraction Data}

When $\mathrm{Sr}^{2+}$ is replaced by $\mathrm{La}^{3+}$ in $\mathrm{LaSrGa}_{3} \mathrm{O}_{7}$, excess (interstitial) oxide ions are introduced into the melilite structure in order to maintain the charge neutrality, instead of inducing vacancies on the $\mathrm{La} / \mathrm{Sr}$ crystalographic site. The structural analysis based on NPD data of $\mathrm{La}_{1.54} \mathrm{Ga}_{0.46} \mathrm{Ga}_{3} \mathrm{O}_{7.27}{ }^{[9]}$ showed that these excess oxide ions enter the pentagonal rings at an interstitial position (O4) close to the ring center (Figure 2a, b, d), which is located between two La/Sr cations along the pentagonal tunnel direction (Figure 2a-b). This transforms one $(\mathrm{Ga} 2)_{4} \mathrm{O}_{4}$ tetrahedron (Figure 2e) with one terminal oxygen $(\mathrm{O} 2)$ and three bridging oxygen (one $\mathrm{O} 1$, two $\mathrm{O} 3$ ) among the five tetrahedra defining the five-fold ring into a trigonal bipyramid $(\mathrm{Ga} 2)_{\mathrm{L}} \mathrm{O}_{5}$ (Figure $2 \mathrm{f}$ ). In order to avoid short contact with interstitial oxygen, the framework oxygen atoms shift towards the adjacent five-fold rings and away from interstitial oxygen (Figure 2c-d). Simultaneously the $\mathrm{La} / \mathrm{Sr}$ cations in the pentagonal tunnel and one 3-connected Ga2 center (Figure 2e) next to the interstitial oxide ion show a displacement towards interstitial oxygen, further stabilizing the interstitial oxygen.
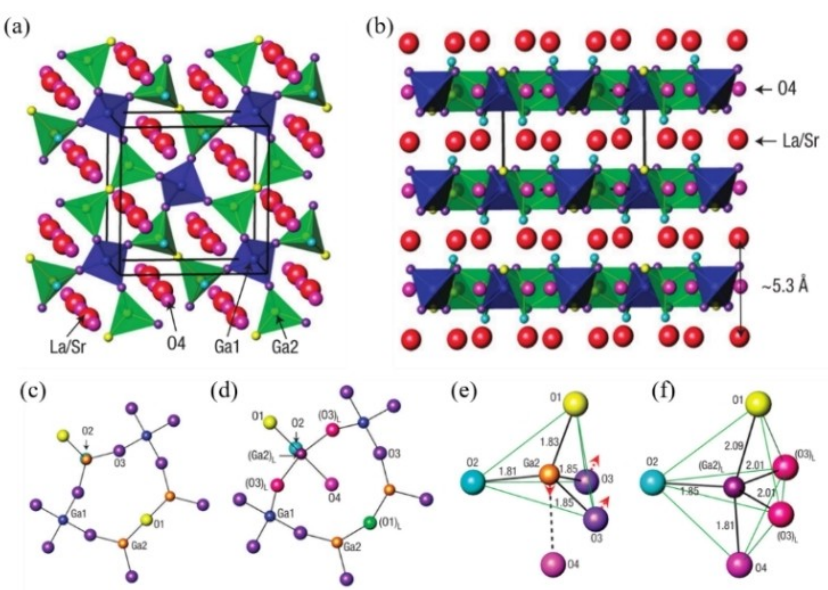

Figure 2. The crystal structure of $\mathrm{La}_{1.54} \mathrm{Sr}_{0.46} \mathrm{Ga}_{3} \mathrm{O}_{7.27}$, showing (a) cornershared $\mathrm{Ga}_{3} \mathrm{O}_{7}$ tetrahedral layers in the $a b$ plane, and (b) the stacking of the $\mathrm{Ga}_{3} \mathrm{O}_{7}$ tetrahedral layers and $(\mathrm{La} / \mathrm{Sr})_{2}$ layers along the $c$ axis with inclusion of interstitial oxygen sites (O4). (c) and (d) are pentagonal rings in the bulk structure and local defect structure around the oxygen interstitial O4 respectively. (e, f) show the $(\mathrm{Ga} 2) \mathrm{O}_{4}$ tetrahedron in the bulk structure and the distorted $(\mathrm{Ga} 2)_{\mathrm{L}} \mathrm{O}_{5}$ trigonal bipyramid in the defect structure, respectively. (a-f adapted from Ref. ${ }^{[9]}$. Copyright 2008, Nature Publishing Group.) 


\subsection{Diversity of Interstitial Oxide Ion Stabilization Mechanism}

Later Tealdi et al. ${ }^{[19]}$ performed static lattice atomistic simulation and Mancini et al. ${ }^{[23]}$ carried out pair distribution function (PDF) analysis on neutron total scattering data of $\mathrm{La}_{1.5} \mathrm{Sr}_{0.5} \mathrm{Ga}_{3} \mathrm{O}_{7.25}$. However, these analyses showed that the energy-favorable interstitial oxygen site is an off-center position in the pentagonal ring, which bonds with one Gal and two $\mathrm{Ga} 2$ atoms (Figure 3b). ${ }^{[19,23]}$ Our recent work on $\mathrm{La}_{1.5} \mathrm{Ca}_{0.5} \mathrm{Al}_{3} \mathrm{O}_{7.25}$ prepared by glass-ceramic method also revealed the existence of such off-center position for oxygen interstitials, ${ }^{[24]}$ in addition to the normal site close to the pentagonal ring center determined from structural analysis using NPD data. ${ }^{\left[{ }^{9]}\right.}$ Therefore, the interstitial oxygen site in the melilite oxide ion conductors is still controversial. More recently, we and Schuett et al. carried out density functional theory (DFT) calculations on $\mathrm{La}_{1.5} \mathrm{Sr}_{0.5} \mathrm{Ga}_{3} \mathrm{O}_{7.25}$, ${ }^{[25,26]}$ respectively, which showed that the interstitial oxygen position obtained from geometry optimization indeed is consistent with the interstitial oxygen site close to the pentagonal ring center determined by our previous structural analysis of

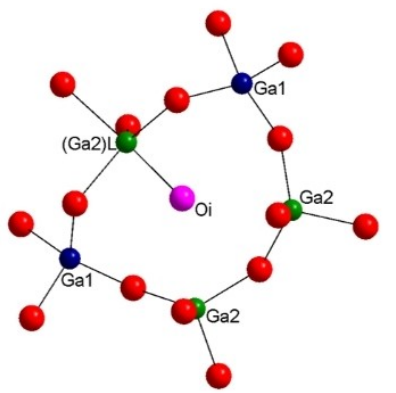

(a) $\mathrm{La}_{1.54} \mathrm{Sr}_{0.46} \mathrm{Ga}_{3} \mathrm{O}_{7.27}$

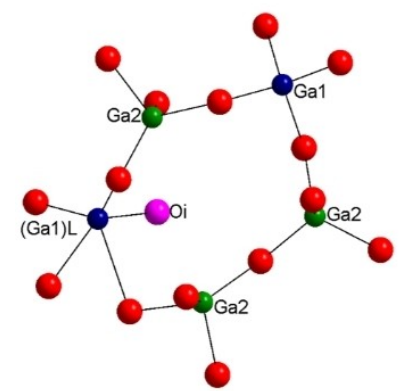

(c) $\mathrm{CeSrGa}{ }_{3} \mathrm{O}_{7.39}$

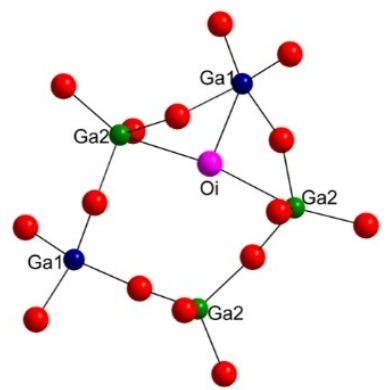

(b) $\mathrm{La}_{1.5} \mathrm{Sr}_{0.5} \mathrm{Ga}_{3.25}$

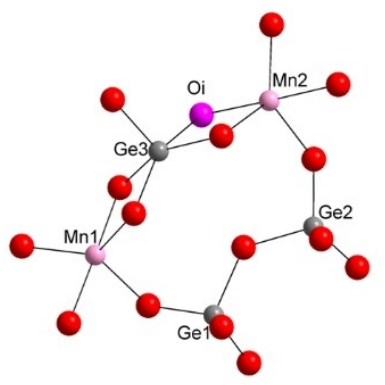

(d) $\mathrm{Sr}_{2} \mathrm{MnGe}_{2} \mathrm{O}_{7.5}$
Figure 3. View of pentagonal rings containing the interstitial oxygen (in purple) in the local defect structures of (a) $\mathrm{La}$
$\mathrm{La}_{1.54} \mathrm{Sr}_{0.46} \mathrm{Ga}_{3} \mathrm{O}_{7.27}$ based on the NPD data. Schuett et al. further studied locally various $\mathrm{La} / \mathrm{Sr}$ cation environments in the melilite structure, which showed there are slightly offcentered positons depending on the local $\mathrm{La} / \mathrm{Sr}$ cation environments. ${ }^{[26]}$ These controversial positions for interstitial oxide ions in these close gallate melilite compositions could be mainly arising from different analytical methods used.

Apart from the donor substitution described above, excess oxygen atoms can be also introduced through oxidation in melilites. In 2014, we prepared the $\mathrm{CeSrGa}_{3} \mathrm{O}_{7}$ melilite material in reducing atmosphere conditions and further reoxidized it at $550{ }^{\circ} \mathrm{C}$ under oxygen flow, resulting in $\mathrm{CeSrGa}_{3} \mathrm{O}_{7.39}$ with a large amount of oxygen interstitials upon the oxidation of $\mathrm{Ce}^{3+}$ into $\mathrm{Ce}^{4+} \cdot{ }^{[27]}$ At $600{ }^{\circ} \mathrm{C}$, the conductivity of $\mathrm{CeSrGa}_{3} \mathrm{O}_{7+\delta}$ varied $-10^{-4} \mathrm{~S} / \mathrm{cm}$ in air, which is -4 orders of magnitude higher than that of $\mathrm{LaSrGa}_{3} \mathrm{O}_{7}$. In situ measurement of the conductivity of $\mathrm{CeSrGa}_{3} \mathrm{O}_{7+\delta}$ versus oxidation time showed that the introduction of interstitial oxide ions did decrease the conductivity, contrary to $\mathrm{La}_{1+x} \mathrm{Sr}_{1-}$ ${ }_{x} \mathrm{Ga}_{3} \mathrm{O}_{7+0.5 x}$ and $\operatorname{Pr}_{1.1} \mathrm{Sr}_{0.9} \mathrm{Ga}_{3} \mathrm{O}_{7.05}$ cases. ${ }^{[20,25]}$ As indicated by structural analysis on NPD data of $\mathrm{CeSrGa}_{3} \mathrm{O}_{7.39}$, unlike the interstitial oxygen in $\mathrm{La}_{1+x} \mathrm{Sr}_{1-x} \mathrm{Ga}_{3} \mathrm{O}_{7+0.5 x}$ entering the 3connected tetrahedral coordination environment (Figure 3ab), the interstitial oxygen in $\mathrm{CeSrGa}_{3} \mathrm{O}_{7.39}$ enters the 4connected $(\mathrm{Ga1}) \mathrm{O}_{4}$ tetrahedron without terminal oxygen and is located in the framework oxygen level in the $\mathrm{Ga}_{3} \mathrm{O}_{7}$ layer along the $c$ axis (Figure 3c). ${ }^{[27]}$ Compared with the 3-connected tetrahedron, the 4-connected tetrahedron does not have flexible rotation and deformation possibility, which places great constraint to the migration of interstitial oxygen. In addition, $\mathrm{Ce}^{3+}$ ions are oxidized into smaller $\mathrm{Ce}^{4+}$ which can form strong chemical bonds with interstitial oxygen and therefore trap the interstitial oxygen. Therefore, interstitial oxygen defects from the oxidation show localization in $\mathrm{CeSrGa}_{3} \mathrm{O}_{7+\delta}$. Similar stabilization of interstitial oxygen in the melilite was also observed in $\mathrm{Sr}_{2} \mathrm{MnGe}_{2} \mathrm{O}_{7.5}$, in which the oxygen interstitials transform part of tetrahedra into 5coordinated polyhedral units forming edge-shared $\mathrm{MnO}_{5}-\mathrm{GeO}_{5}-\mathrm{MnO}_{5}$ trimers (Figure 3d). ${ }^{[28]}$

\section{Migration of Interstitial Oxide Ions}

Initially the interstitial oxygen migration in gallate melilite was analyzed based on the ellipsoid plot of its high temperature thermal parameters obtained from variable temperature NPD data. ${ }^{\left[{ }^{9]}\right.}$ As the path along the pentagonal tunnel is blocked by large $\mathrm{La} / \mathrm{Sr}$ cations, the migration of the interstitial oxygen was proposed to occur within the tetrahedral layer via hopping among the pentagonal rings, which passes the different oxygen bottlenecks. As the static crystal structure shows that the bottlenecks formed by 4-connected and 3-connected $\mathrm{GaO}_{4}$ 
tetrahedra are larger than that formed by two 3-connected $\mathrm{GaO}_{4}$ tetrahedra, the preferable migration paths were proposed to be between 4-connected and 3-connected $\mathrm{GaO}_{4}$ tetrahedra, as labelled in green in Figure $4 a^{\left[{ }^{[9]}\right.}$ By rotation, deformation and releasing of the excessly-bonded oxide ion, the $\mathrm{GaO}_{4}$ tetrahedron transports an interstitial oxide ion from one pentagonal ring to a neighboring ring. The existence of a terminal oxygen in 3-connected $\mathrm{GaO}_{4}$ tetrahera ensures the rotation and deformation flexibility, which is favorable to widen the oxygen bottlenecks allowing oxygen hopping. Therefore, $\mathrm{Ga}^{3+}$ ions with variable coordination number and rotation and deformation flexibility of two-dimensionally connected tetrahedral network are key factors for both the stabilization and migration of interstitial oxide ions in melilites.

Later, Tealdi et al. conducted static lattice and molecular dynamic (MD) atomistic simulations on the oxide ion migration mechanism in $\mathrm{La}_{1.5} \mathrm{Sr}_{0.5} \mathrm{Ga}_{3} \mathrm{O}_{7.25}$ melilite based on the interatomic potential method. ${ }^{[19]}$ Their MD simulations confirmed that the migration of oxide ions is highly anisotropic and confined within the $\mathrm{Ga}_{3} \mathrm{O}_{7}$ tetrahedral layer. Moreover, the diffusion of oxygen ions between $\mathrm{Ga}_{3} \mathrm{O}_{7}$ layers is not allowed as large-size $\mathrm{La} / \mathrm{Sr}$ cations are blocking the way. In 2005, Wei et al. studied conductivity of single crystals $\left[\mathrm{A}_{1+}\right.$ $\left.{ }_{x} \mathrm{~B}_{1-x}\right]_{2}[\mathrm{Ga}]_{2}\left[\mathrm{Ga}_{2} \mathrm{O}_{7+x / 2}\right]_{2} \quad(0 \leq x \leq 0.5) \quad(\mathrm{A}=\mathrm{La}, \mathrm{Nd} ; \mathrm{B}=\mathrm{Ca}$, $\mathrm{Sr}$ ), confirming the strong anisotropic ion conduction in the melilite structure. ${ }^{[29]}$ e.g. The high ionic conductivity of $\sim 0.036 \mathrm{~S} / \mathrm{cm}$ at $850{ }^{\circ} \mathrm{C}$ for $\mathrm{La}_{1.5} \mathrm{Sr}_{0.5} \mathrm{Ga}_{3} \mathrm{O}_{7.25}$ perpendicular to $c$ axis is comparable to YSZ, but is only $0.008 \mathrm{~S} / \mathrm{cm}$ along the $c$ direction, which also indicated the preferred oxide ion diffusion pathway is intra-layer rather than inter-layer. ${ }^{[29]}$

However the molecular dynamics simulation reveals that interstitial oxide ion migration in $\mathrm{La}_{1.5} \mathrm{Sr}_{0.5} \mathrm{Ga}_{3} \mathrm{O}_{7.25}$ occurs through the synergistic knock-on mechanism, which involves collision and position exchange between interstitial and frame- (a)

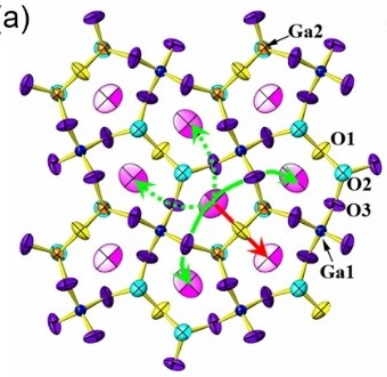

(b)

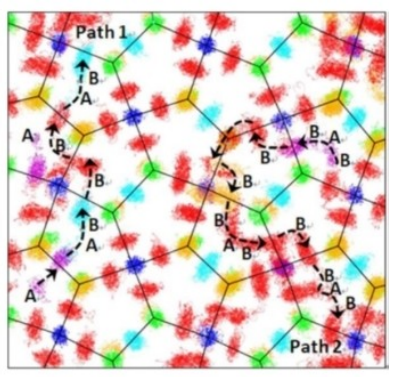

Figure 4. (a) Ellipsoid model of the high-temperature $\left(800^{\circ} \mathrm{C}\right)$ crystal structure for $\mathrm{La}_{1.54} \mathrm{Sr}_{0.46} \mathrm{Ga}_{3} \mathrm{O}_{7.27}$ along the $c$ axis. (b) Interstitial oxide ion migration paths identified from scatter plot of oxygen-ion positions in one $\mathrm{Al}_{3} \mathrm{O}_{7}$ tetrahedral layer viewed along the $\mathrm{c}$ axis from $\mathrm{MD}$ simulations of $\mathrm{La}_{1.5} \mathrm{Ca}_{0.5} \mathrm{Al}_{3} \mathrm{O}_{7.25}$. (a adapted from Ref. ${ }^{[9]}$. Copyright 2008, Nature Publishing Group. b adapted from Ref. ${ }^{[24]}$. Copyright 2019, American Chemical Society.) work oxygen atoms. Such synergistic oxide ion transport mechanism has been confirmed in $\mathrm{La}_{1+x} \mathrm{Ca}_{1-x} \mathrm{Al}_{3} \mathrm{O}_{7+0.5 x}$ aluminate melilite oxide ion conductors (Figure $4 \mathrm{~b}$ ). ${ }^{[24]}$ In this system, we confirmed the presence of interstitial oxide ions in melilite for the first time through solid-state ${ }^{27} \mathrm{Al}$ nuclear magnetic resonance (NMR) spectroscopy, and revealed the dynamic exchange process between the adjacent 5-coordinated $\mathrm{Al}$ sites through variable temperature ${ }^{27} \mathrm{Al}$ solid-state NMR magic angle spinning (MAS) spectroscopy. Apart from ${ }^{27} \mathrm{Al}$ solid-state NMR, we also attempted to perform ${ }^{71} \mathrm{Ga}$ solidstate NMR spectoscopy on gallate melilites oxide ion conductors. However ${ }^{71} \mathrm{Ga}$ solid-state NMR experiments did not allow stoichiometric $\mathrm{LaSrGa}_{3} \mathrm{O}_{7}$ and non-stoichiometric $\mathrm{La}_{1.5} \mathrm{Sr}_{0.5} \mathrm{Ga}_{3} \mathrm{O}_{7.25}$ to be distinguished. The quadrupolar ${ }^{71} \mathrm{Ga}$ nucleus is indeed much more complex to study, even using high magnetic field facilities, and therefore awaits further investigation using more advanced instrumentation.

More recently, Schuett et al. investigate interstitial oxide ion migration in $\mathrm{La}_{1.5} \mathrm{Sr}_{0.5} \mathrm{Ga}_{3} \mathrm{O}_{7.25}$ melilite structure using DFT and Kinetic Monte Carlo (KMC) simulations, and taking into account various $\mathrm{La} / \mathrm{Sr}$ cation local environments. ${ }^{[26]}$ The results of the DFT calculation showed oxide ions migrate indeed through the interstitialcy mechanism rather than a direct interstitial jump between adjacent rings, and the calculated migration barriers within $0.15-0.35 \mathrm{eV}$ depending on the local A cation environments and decreasing with the increasing lanthanum content. These values is lower than the experimental value $(0.42 \mathrm{eV})$ for $\mathrm{La}_{1.54} \mathrm{Sr}_{0.46} \mathrm{Ga}_{3} \mathrm{O}_{7.27}$ in the high temperature region above $600^{\circ} \mathrm{C} .{ }^{[9]}$ The $\mathrm{KMC}$ simulations based on DFT calculations indicated that the macroscopic activation energy is essentially determined by the interaction of the interstitials with the local cation and anion environment, which explains the decrease of the activation energy with the increasing lanthanum content. Therefore, the local A cation environment could play a crucial role in determining interstitial ion migration barrier and the oxide ion conductivity. ${ }^{[26]}$

\section{Cationic Size Effect}

Inspired by the identification of interstitial oxide ion conduction in $\mathrm{La}_{1+x} \mathrm{Sr}_{1-x} \mathrm{Ga}_{3} \mathrm{O}_{7+0.5 x}$, melilites with different trivalent rare earth ions and divalent alkaline earth metal ions has become a popular system for exploring new interstitial oxide ion conductors. In 2011, Liu et al. attempted to prepare a series of $\mathrm{Ln}_{1+x} \mathrm{Sr}_{1-x} \mathrm{Ga}_{3} \mathrm{O}_{7+0.5 x}(\mathrm{Ln}=\mathrm{La}, \mathrm{Pr}, \mathrm{Nd}, \mathrm{Sm}, \mathrm{Eu}, \mathrm{Gd}$, $\mathrm{Dy}, \mathrm{Yb}$ and $\mathrm{Y}$ ) materials and found that the lanthanide cations smaller than $\mathrm{La}^{3+}$ are much less favorable for stabilizing the interstitial oxide ions (Figure 5a). ${ }^{[30]}$ Apart from $\mathrm{La}_{1+x} \mathrm{Sr}_{1-}$ ${ }_{x} \mathrm{Ga}_{3} \mathrm{O}_{7+0.5 x}$, the $\mathrm{Ln}=\operatorname{Pr}$ compositions achieved the highest interstitial oxide ion content among $\operatorname{Ln}_{1+x} \mathrm{Sr}_{1-x} \mathrm{Ga}_{3} \mathrm{O}_{7+0.5 x}$ at 

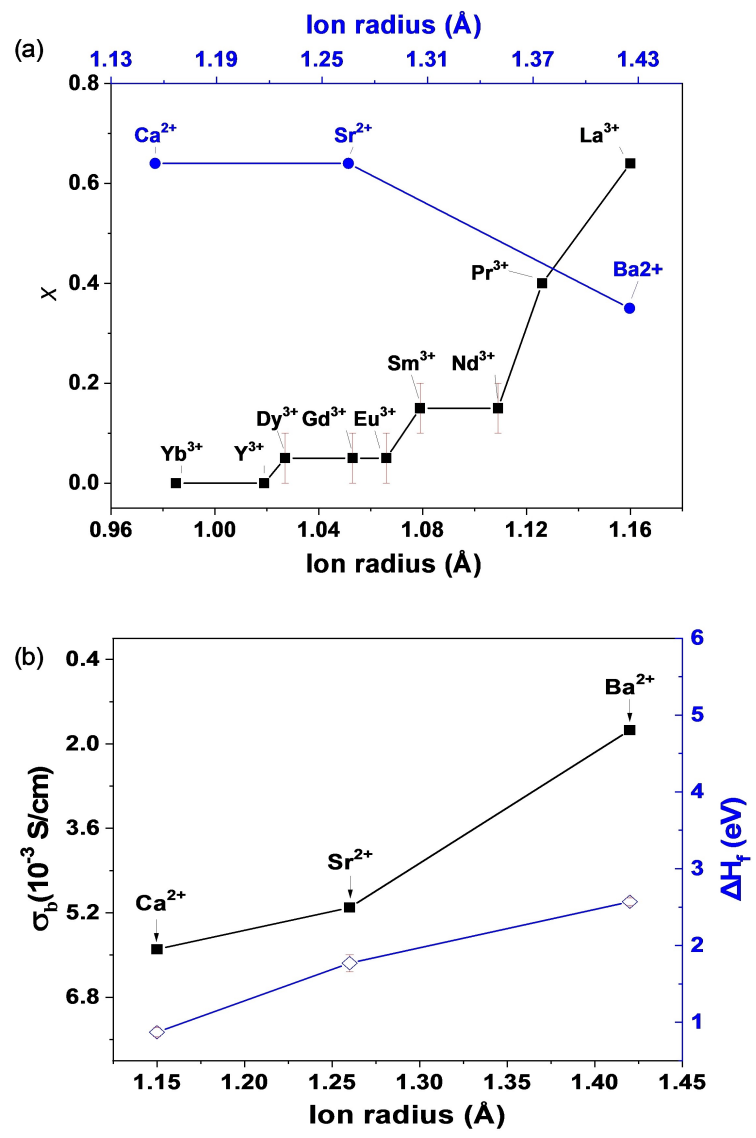

Figure 5. (a) $\mathrm{Ln}^{3+}$ and $\mathrm{M}^{2+}$ radius dependence of the maximum interstitial oxide ion content $(x)$ allowed in $L n_{1+x} \mathrm{Sr}_{1-x} \mathrm{Ga}_{3} \mathrm{O}_{7+0.5 x}$ (filled black squares) and $\mathrm{La}_{1+x} M_{1-x} \mathrm{Ga}_{3} \mathrm{O}_{7+0.5 x}$ (filled blue circles). (b) Formation energies of oxygen interstitial defects $\left(\Delta \mathrm{H}_{\mathrm{f}}\right)$ in $\mathrm{La} M \mathrm{Ga}_{3} \mathrm{O}_{7}$ and bulk conductivities of $\mathrm{La}_{1.35} M_{0.65} \mathrm{Ga}_{3} \mathrm{O}_{7.175}$ at $600^{\circ} \mathrm{C}$.

$x=0.4$, of which conductivity reached $-0.1 \mathrm{~S} / \mathrm{cm}$ at $800^{\circ} \mathrm{C} \cdot{ }^{[31]}$ So far, the synthesis was performed via traditional high temperature solid state route and no melilite phase could be formed for the $\mathrm{Ln}=\mathrm{Yb}$ and $\mathrm{Y}$ compositions. These results indicate that smaller Ln cation hardly maintain the melilite structure at high $\mathrm{Ln}^{3+}$ concentration. In other words, a cationic size effect takes place on the stability of interstitial oxide ions in gallate melilites.

On the other hand, we modified the size of alkaline earth metal ions in $\mathrm{La}_{1+x} M_{1-x} \mathrm{Ga}_{3} \mathrm{O}_{7+0.5 x}(M=\mathrm{Ca}, \mathrm{Sr}, \mathrm{Ba})$ and examined the capacity of accommodating interstitial oxide ions from the experimental and defect formation energy calculation (Figure 5a). ${ }^{[32]}$ When the alkaline earth metal ions are smaller $\mathrm{Ca}$ and $\mathrm{Sr}$, the solid solution limits are close to $x=0.64$. However, the solid solution limit of $\mathrm{La}_{1+x} \mathrm{Ba}_{1-x} \mathrm{Ga}_{3} \mathrm{O}_{7+0.5 x}$ only extends up to $x=0.35$, which is about half of the limit value in $\mathrm{Sr}$ or $\mathrm{Ca}$ compositions. DFT calculations showed that in $\mathrm{LaMGa}_{3} \mathrm{O}_{7}$ the interstitial oxygen defect formation energy
$\left(\Delta \mathrm{H}_{\mathrm{f}}\right)$ changes systematically with the size of the $\mathrm{M}^{2+}$ cation: $\Delta \mathrm{H}_{(\mathrm{Ba})}^{\mathrm{f}} \quad(2.52-2.62 \mathrm{eV})>\Delta \mathrm{H}_{(\mathrm{rr})}^{\mathrm{f}} \quad(1.66-1.88 \mathrm{eV})>\Delta \mathrm{H}_{(\mathrm{Ca})}^{\mathrm{f}}$ $(0.81-0.93 \mathrm{eV})$, i.e. the capacity of $\mathrm{LaMGa}_{3} \mathrm{O}_{7}$ to accommodate interstitial oxide ion defects is $\mathrm{Ca}>\mathrm{Sr}>\mathrm{Ba}$ (Figure 5b). The conductivity and interstitial oxide ions mobility of $\mathrm{La}_{1.35} \mathrm{M}_{0.65} \mathrm{Ga}_{3} \mathrm{O}_{7.175}$ compositions with the same interstitial oxygen contents also followed the same trend (Figure 5b).

The variations of solid solution limits and conductivity versus $\mathrm{A}$-cation sizes in $\mathrm{Ln}_{1+x} \mathrm{Sr}_{1-x} \mathrm{Ga}_{3} \mathrm{O}_{7+0.5 x}$ and $\mathrm{La}_{1+x} \mathrm{M}_{1-}$ ${ }_{x} \mathrm{Ga}_{3} \mathrm{O}_{7+0.5 x}$ indicate that too large or too small $\mathrm{A}$ cations are not favorable for interstitial oxide ion conduction. This cationic size effect on the capacity to accommodate interstitial oxide ions in gallate melilites has been understood from the associated local structural relaxation required for the incorporation of interstitial oxide ion defects. The accommodation of interstitial oxide ions in the five-fold rings of the melilite structure causes size expansion of the interstitials-containing pentagonal ring and simultaneous size contraction of the adjacent interstitial-free pentagonal rings. This local structure relaxation makes the stabilization and migration of interstitial oxide ions in the structure highly dependent on the size of cations sitting in the five-fold tunnels. On one hand, small-size A cations could make the pentagonal ring too small to accommodate interstitial oxide ions. On the other hand, large A cations inhibit the size expansion of the neighboring pentagonal ring and thus reduce its capability to accommodate interstitial oxide ions and the mobility of interstitial oxide ions among the pentagonal rings. Large A cations in the gallate melilite structure need to have intermediate sizes to facilitate the stability and migration of interstitial oxide ions, which should not be too large or too small, in order to adapt to the simultaneous size expansion and contraction of the pentagonal rings caused by the incorporation of interstitial oxide ions.

\section{Chemical Bonding Effect}

The above-mentioned stabilization and migration mechanisms for oxygen interstitials in the melilite structure mainly consider electrostatic Coulomb interactions among the framework and interstitial atoms, which depends on the ionic charge and size. The formation and motion of the oxygen defects in the host lattices usually is a consequence of synergic chemical interaction among the framework atoms and defects including both coulomb force and orbital overlapping/covalent bonding. Therefore, the total electronic energy should be taken into consideration for a better understanding of the defect structure based on the interatomic chemical bonding around the interstitial defects in the melilites.

We performed density functional theory (DFT) calculations of electronic structures for $\mathrm{La}_{1+x} \mathrm{Sr}_{1-x} \mathrm{Ga}_{3} \mathrm{O}_{7+0.5 x}(x=0$ and 0.5$)$ melilite compositions. The geometry optimization for 
$\mathrm{La}_{1.5} \mathrm{Sr}_{0.5} \mathrm{Ga}_{3} \mathrm{O}_{7.25}$ indeed confirmed the relaxation of framework atoms in the defect structure solved from NPD data. ${ }^{[25]}$ These electronic structure calculations provided new insight into the accommodation and migration of oxygen interstitials in $\mathrm{La}_{1+x} \mathrm{Sr}_{1-x} \mathrm{Ga}_{3} \mathrm{O}_{7+0.5 x}$ melilites. Interstitial oxide ions in the site close to the center of the pentagonal ring allows the formation of a covalent bond with one 3-connected tetrahedral Ga2a (Figure 6a-c). The large $\mathrm{La}^{3+}$ or $\mathrm{Sr}^{2+}$ cations located below and above the oxygen interstitial form ionic bonds with the interstitial oxygen. The ionic bonds with $\mathrm{La}^{3+}$ or $\mathrm{Sr}^{2+}$ cations have no specific direction requirement and can tolerate the synergic $\mathrm{La} / \mathrm{Sr}-\mathrm{O}$ distance expansion and contraction owing to the displacements of the framework oxygen atoms towards the neighboring pentagonal ring. Thus, the ionic bonding characteristic of large electropositive cations with oxygen appears as another important factor to the accommodation of oxygen interstitials. More importantly, the electronic structure features a synergistic weak anti-bonding interaction among the interstitial oxide ion $\left(\mathrm{O}_{\mathrm{i}}\right)$ and the framework oxygen atom $\left(\mathrm{O}_{\mathrm{f}}\right)$ (Figure $6 \mathrm{~d}$ ). The $\mathrm{O}_{\mathrm{i}}-\mathrm{O}_{\mathrm{f}}$ anti-bonding interaction pushes $\mathrm{O}_{\mathrm{i}}$ towards $\mathrm{Ga} 2 \mathrm{a}$ ions, enhancing the covalent bond between $\mathrm{Ga} 2 \mathrm{a}$ and $\mathrm{O}_{\mathrm{i}}$, which contributes to the stabilization of interstitial oxide ions. Meanwhile, the antibonding interactions between $\mathrm{O}_{\mathrm{i}}$ and $\mathrm{O}_{\mathrm{f}}$ make interstitial and framework oxygen atoms highly active, which facilitates the migration of interstitial oxide ions.

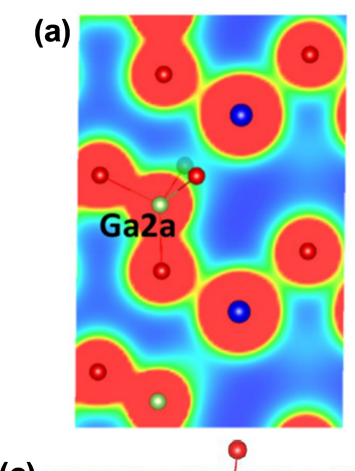

(c)

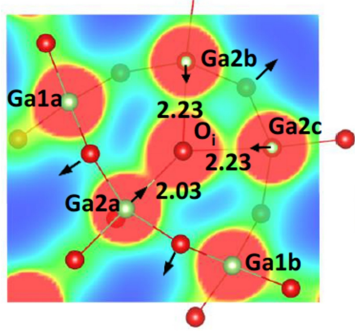

(b)

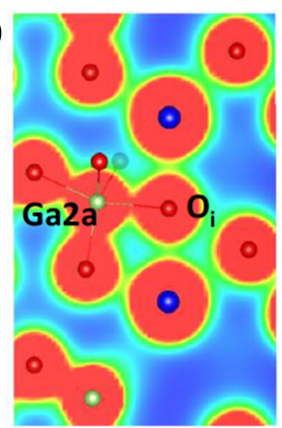

(d)

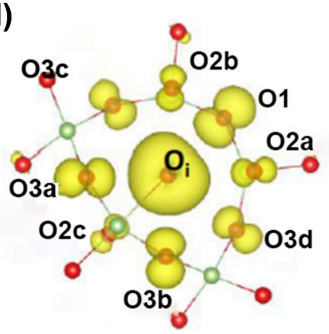

Figure 6. Total electron density map of (a) $\mathrm{LaSrGa}_{3} \mathrm{O}_{7}$ and (b) $\mathrm{La}_{1.5} \mathrm{Sr}_{0.5} \mathrm{Ga}_{3} \mathrm{O}_{7.25}$ viewed along the direction, (c) and the $\mathrm{O}_{\mathrm{i}}$-containing pentagonal ring in $\mathrm{La}_{1.5} \mathrm{Sr}_{0.5} \mathrm{Ga}_{3} \mathrm{O}_{7.25}$ viewed along the [001] direction. (d) Partial electron density map of $\mathrm{O}_{\mathrm{i}}-\mathrm{O}_{\mathrm{f}}$ antibonding orbits in $\mathrm{La}_{1.5} \mathrm{Sr}_{0.5} \mathrm{Ga}_{3} \mathrm{O}_{7.25}$ viewed along the [001] direction. (a-d adapted from Ref. ${ }^{[25]}$. Copyright 2019, Wiley-VCH Verlag Gmbh.)
Following the tunnel-cation size effect described in the section above, we examined the phase formation in $\mathrm{La}_{1+x} \mathrm{~Pb}_{1-}$ ${ }_{x} \mathrm{Ga}_{3} \mathrm{O}_{7+0.5 x}$, where $\mathrm{Pb}^{2+}$ has a cationic size (1.29 $\AA$ ) close to $\mathrm{Sr}^{2+}(1.26 \AA)$ but with $6 \mathrm{~s}^{2}$ lone pair electrons. The stoichiometric parent $\mathrm{LaPbGa}_{3} \mathrm{O}_{7}$ can be synthesized but the solid solubility limit of $\mathrm{La}_{1+x} \mathrm{~Pb}_{1-x} \mathrm{Ga}_{3} \mathrm{O}_{7+0.5 x}$ was found to be approximately $x=0.1$. Thus, the oxygen interstitials are hardly incorporated into the structure by $\mathrm{La}^{3+}$ substitution for $\mathrm{Pb}^{2+},{ }^{[25]}$ in great contrast with $\mathrm{La}_{1+x} \mathrm{Sr}_{1-x} \mathrm{Ga}_{3} \mathrm{O}_{7+0.5 x}$. In the $\mathrm{LaPbGa}_{3} \mathrm{O}_{7}$ material, the electronic structure calculation shows that the $6 s^{2}$ lone pair electrons of $\mathrm{Pb}$ are not inert electrons but do participate to chemical bonding. In fact, the $\mathrm{Pb} 6 \mathrm{~s}$ and $\mathrm{O}$ $2 \mathrm{p}$ orbits form the antibonding orbits (Figure $7 \mathrm{a}$ ) and covalent bonding (Figure $7 \mathrm{~b}$ ), both of which are occupied. The electrons around $\mathrm{Pb}$ in the bonding state are symmetrically distributed. While the electron distribution in the antibonding state is asymmetric being projected into the pentagonal ring. Unlike the ionicity of the $\mathrm{La}^{3+} / \mathrm{Sr}^{2+}-\mathrm{O}$ bond, this directionally covalent antibonding state between $\mathrm{Pb}$ and $\mathrm{O}$ directly inhibits the incorporation of interstitial oxygen atoms into the pentagonal ring, and cannot tolerate simultaneous size expansion and contraction of the pentagonal rings.

In summary, the DFT-based electronic structure calculations of $\mathrm{LaSrGa}_{3} \mathrm{O}_{7}$ and $\mathrm{LaPbGa}_{3} \mathrm{O}_{7}$-based compositions revealed ionic and covalent bonding control of oxygen interstitial defects and cooperatively weak antibonding interaction between interstitial and framework oxygen atoms. From Coulomb interactions point of view, the open structure and the variable coordination-number polyhedral network with

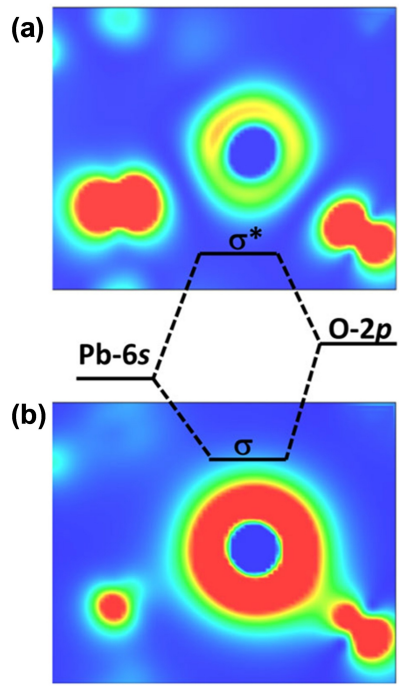

Figure 7. Partial electron density map of (a) the antibonding and (b) bonding interaction between $\mathrm{Pb}$ and $\mathrm{O}$ around along the [010] direction in $\mathrm{LaPbGa}_{3} \mathrm{O}_{7}$ (the vertical direction in $(\mathrm{a}-\mathrm{b})$ is paralle to tunnel). (a-b adapted from Ref. ${ }^{[25]}$. Copyright 2019, Wiley-VCH Verlag Gmbh.) 
terminal oxide anion ensuring flexibility (rotation and deformation), the size of A cations are key for the stablization and migration of interstitial oixde ions in the gallate melilites. Moreover, the coupling among the highly electropositive elements favor unidirectional ionic bonding, covalent polyhedral network providing additionally directional bonding, as well as antibonding interaction from framework oxygen atoms could place additional constraints for the stabilization of mobile interstitial oxide ion defects in the gallate melilite structure from chemical bonding point of view. This new chemical bonding effect together with the cationic size effect both complement the stabilization and migration mechanisms of interstitial oxide ions in melilites.

\section{Interstitial Oxide Ion Ordering}

In $\mathrm{La}_{1+x} \mathrm{Sr}_{1-x} \mathrm{Ga}_{3} \mathrm{O}_{7+0.5 x}$ and $\mathrm{La}_{1+x} \mathrm{Ca}_{1-x} \mathrm{Ga}_{3} \mathrm{O}_{7+0.5 x}$ solid solutions, the increase of the interstitial oxide ion content can lead to the ordering of interstitial oxide ions among the pentagonal rings, which reduces the symmetry from tetragonal (T) to (pseudo) orthorhombic $(\mathrm{O})$ and therefore the associated conductivity. ${ }^{[20,33]}$ At room temperature (RT), the $\mathrm{T}$ polymorph in $\mathrm{La}_{1+x} \mathrm{Ca}_{1-x} \mathrm{Ga}_{3} \mathrm{O}_{7+0.5 x}$ can extend up to $x=0.55$, above which the $\mathrm{O}$ polymorph forms until $x=0.64$ (Figure 8a), which transform to the $\mathrm{T}$ phase above $600^{\circ} \mathrm{C}$ (Figure 8b). Similarly, for $\mathrm{La}_{1+x} \mathrm{Sr}_{1-x} \mathrm{Ga}_{3} \mathrm{O}_{7+0.5 x}$ at RT, the $\mathrm{T}$
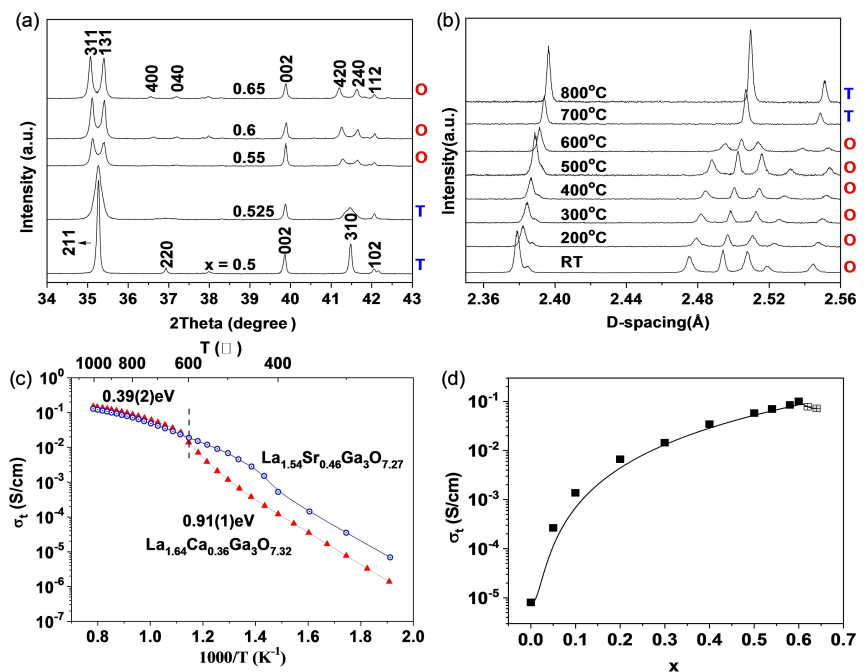

Figure 8. (a) XRD patterns of $\mathrm{La}_{1+x} \mathrm{Ca}_{1-x} \mathrm{Ga}_{3} \mathrm{O}_{7+0.5 x}(x \geq 0.5)$ with $h k l$ indices labelled for the tetragonal $(\mathrm{T})$ and orthorhombic $(\mathrm{O})$ phases. (b) Variable temperature (VT) time-of-flight NPD data for $\mathrm{La}_{1.64} \mathrm{Sr}_{0.36} \mathrm{Ga}_{3} \mathrm{O}_{7.32}$. (c) Arrhenius plot of total conductivity for $\mathrm{La}_{1.64} \mathrm{Ca}_{0.36} \mathrm{Ga}_{3} \mathrm{O}_{7.32}$ compared with $\mathrm{La}_{1.54} \mathrm{Sr}_{0.46} \mathrm{Ga}_{3} \mathrm{O}_{7.27}$. (d) The compositional dependency of conductivity for $\mathrm{La}_{1+x} \mathrm{Sr}_{1-x} \mathrm{Ga}_{3} \mathrm{O}_{7+0.5 x}$ at $800^{\circ} \mathrm{C}$. (a-c adapted from Ref., ${ }^{[33]}$ Copyright 2010, Wiley-Blackwell. d adapted from Ref. ${ }^{[20]}$. Copyright 2010, American Chemical Society.) phase extends up to $x=0.6$ and the $\mathrm{O}$ phase form for $0.6<$ $x \leq 0.64$, which evolves to the $\mathrm{T}$ phase above $565^{\circ} \mathrm{C} .^{[20]}$ Below the $\mathrm{O}-\mathrm{T}$ phase transition temperature, the ordering of interstitial oxide ions reduces the mobility of interstitial oxide ions as the ordered interstitials can block themselves each other and therefore the conductivity (Figure 8c). In the high temperature region where the interstitial oxide ions are disordered, the conductivity decreases with the interstitial oxide ion content at high concentration of interstitial oxide ion owing to the blocking effect (Figure 8d). ${ }^{[20]}$

When the interstitial oxide ions ordering takes place among the pentagonal rings, half of that pentagonal rings is partially filled by the oxide ions and the other half is completely empty, which leads to the doubling of the cell along the diagonal line of the tetragonal $a b$ plane, (Figure 9a). The partially filled pentagonal rings are located in two neighboring pentagonal tunnels sharing the $\mathrm{Ga}_{2} \mathrm{O}_{7}$ dimer. Apart from the ordering along the $\langle 110\rangle$ axis, selected area electron diffraction also evidenced the doubling of the tetragonal $c$ axis, indicating that interstitial oxide ion ordering occurs also along the stacking direction. When one oxygen interstitial fills a pentagonal ring, the rings above and below it in the same tunnel, as well as the rings next to the $\mathrm{O}_{\mathrm{i}}$-filled ring within the same tetrahedral layer, do not allow for the incorporation of oxygen interstitial, according to the structural relaxation described above. Therefore, the interstitial oxide ions could be distributed in a zigzag manner at the sites in two neighboring pentagonal tunnels sharing $\mathrm{Ga}_{2} \mathrm{O}_{7}$ dimer (Figure 9b), i.e. along a single pentagonal tunnel in these two adjacent tunnels within a single tetragonal cell, every two pentagonal rings are filled by one interstitial oxide ion and the other half tunnels are empty. This is speculated to be the maximum interstitial oxide ion concentration geometrically allowed in the melilite structure. (a)

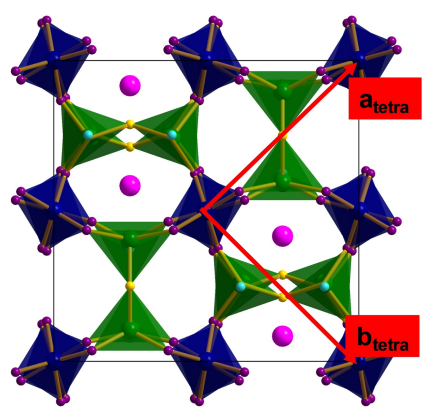

(b)

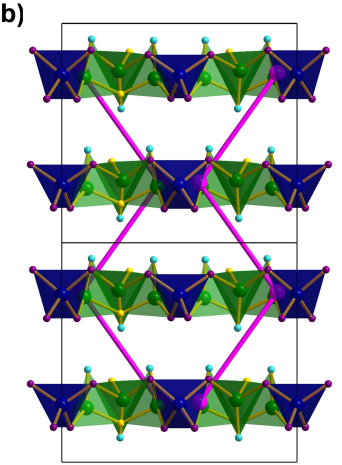

Figure 9. Crystal structure of the orthorhombic polymorph showing ordered interstitial oxygen in gallate melilite structure viewed along (a) [001] and (b) [100] directions. The red arrows in (a) mark the $a$ and $b$ axes in the tetragonal phase with disordered oxygen interstitials and the pink lines in (b) illustrate the zigzag-shape alternate distribution of interstitial oxide atom within two adjacent pentagonal tunnels sharing $\mathrm{Ga}_{2} \mathrm{O}_{7}$ dimers. 
In other words, in $\mathrm{La}_{1+x} \mathrm{M}_{1-x} \mathrm{Ga}_{3} \mathrm{O}_{7+0.5 x}$, theoretically $\mathrm{M}^{2+}$ cations can be fully replaced by $\mathrm{La}^{3+}$ to form $\mathrm{La}_{2} \mathrm{Ga}_{3} \mathrm{O}_{7.5}$. However, the hypothetic $\mathrm{La}_{2} \mathrm{Ga}_{3} \mathrm{O}_{7.5}$ is not accessible so far.

\section{Glass Crystallization Route to New Melilite Oxide Ion Conductors}

As mentioned in the cationic size effect section, when $L n$ is smaller than $\mathrm{La}^{3+}$, the $L n$ substitution for $\mathrm{Sr}$ in $L n_{1+x} \mathrm{Sr}_{1-}$ ${ }_{x} \mathrm{Ga}_{3} \mathrm{O}_{7+0.5 x}$ becomes more difficult and it is difficult to synthesize interstitial oxide ion conductors through the traditional ceramic route. Nevertheless, thanks to the development of the contactless preparation using the aerodynamic levitation coupled to laser heating (AL-LH) system, we successfully elaborated fully dense ceramics of $L n_{1+x} \mathrm{Sr}_{1-x} \mathrm{Ga}_{3} \mathrm{O}_{7+\delta}(L n=$ $\mathrm{Eu}, \mathrm{Gd}, \mathrm{Tb}, x=0.4-0.6)$ melilite oxide ion conductors using the recent full crystallization from bulk glass approach, initially developed to access new optical materials. ${ }^{[34-40]}$ The resulting ceramics with micrometer scale crystallites retained some transparence in the visible and near infrared ranges, owing to their full density (no porosity) and limited birefringence effect (Figure 10a-b). ${ }^{[22]}$ During the preparation step using the ALLH system, the samples are heated up to their melting
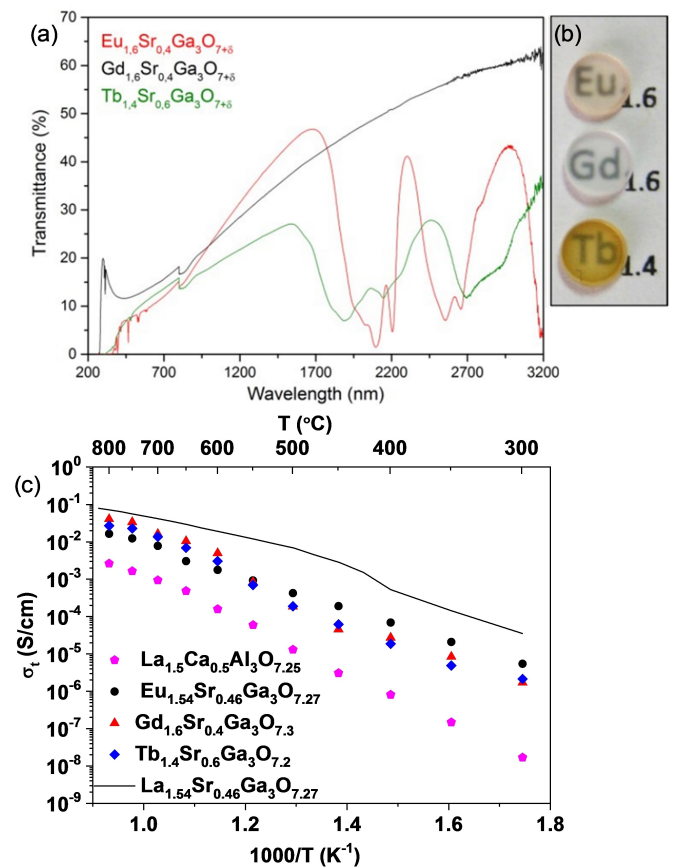

Figure 10. (a) Optical ransmittance curves of $\mathrm{Eu}_{1.6} \mathrm{Sr}_{0.4} \mathrm{Ga}_{3} \mathrm{O}_{7.3}$, $\mathrm{Gd}_{1.6} \mathrm{Sr}_{0.4} \mathrm{Ga}_{3} \mathrm{O}_{7.3}$ and $\mathrm{Tb}_{1.4} \mathrm{Sr}_{0.4} \mathrm{Ga}_{3} \mathrm{O}_{7.3}$ transparent ceramics elaborated by full crystallization from glass and (b) photographs of the corresponding beads. (c) Arrhenius plots of total conductivities of $\mathrm{La}_{1.54} \mathrm{Sr}_{0.46} \mathrm{Ga}_{3} \mathrm{O}_{7.27}$, $\mathrm{La}_{1.5} \mathrm{Ca}_{0.5} \mathrm{Al}_{3} \mathrm{O}_{7.25}, \mathrm{~Tb}_{1.4} \mathrm{Sr}_{0.6} \mathrm{Ga}_{3} \mathrm{O}_{7.2}, \mathrm{Gd}_{1.6} \mathrm{Sr}_{0.4} \mathrm{Ga}_{3} \mathrm{O}_{7.3}$ and $\mathrm{Eu}_{1.54} \mathrm{Sr}_{0.46} \mathrm{O}_{7.27}$. (a-c adapted from Ref. ${ }^{[2]}$. Copyright 2018, Royal Society of Chemistry.) temperature by two $\mathrm{CO}_{2}$ lasers whereas aerodynamic levitation of the melted bead (a few milimeters of diameter) is ensured by a gas flow. The sample is subsequently quenched at a few hundreds of degrees per seconds via switching off the lasers, which can lead to glass forming of some original compositions with a limited amount of glass formers. In a second step, the glass is heated above its glass transition temperature to proceed to full crystallization, such leading to ceramic samples. This innovative bulk glass crystallization route, which can lead to fully dense ceramics with thin grain boundary, ${ }^{[22,24]}$ can be considered as a soft chemistry synthesis process to prepare metastable phases which are not accessible via classic solid state reaction.

Despite the fully dense feature, the thin grain boundaries and the high bulk conductivity of $\sim 0.01 \mathrm{~S} / \mathrm{cm}$ at $470{ }^{\circ} \mathrm{C}$, the $\mathrm{Ln}_{1+x} \mathrm{Sr}_{1-x} \mathrm{Ga}_{3} \mathrm{O}_{7+\delta}(\mathrm{Ln}=\mathrm{Eu}, \mathrm{Gd}, \mathrm{Tb}, x=0.4-0.6)$ ceramics synthesized by glass crystallization exhibit total conductivities much worse than that of $\mathrm{La}_{1.54} \mathrm{Sr}_{0.46} \mathrm{Ga}_{3} \mathrm{O}_{7.27}$ (Figure 10c). The reason for this lies (i) in the smaller $\mathrm{Ln}$ nature of such prepared melilites but also in their metastability: these materials decompose into the stoichiometric melilite phase along the grain boundary at high temperature and therefore form thin but highly resistive grain boundaries. Inspired by the synthesis of transparent $\mathrm{Ln}_{1+x} \mathrm{Sr}_{1-x} \mathrm{Ga}_{3} \mathrm{O}_{7+\delta}(\mathrm{Ln}=\mathrm{Eu}, \mathrm{Gd}, \mathrm{Tb})$ melilite oxide ion conductors, we then successfully prepared the aluminate melilite oxide ion conductors $\mathrm{La}_{1+x} \mathrm{Ca}_{1-x} \mathrm{Al}_{3} \mathrm{O}_{7+0.5 x}$ $(x=0 \sim 0.5)$, which has low cost advantages but cannot be prepared through the traditional solid state reaction. ${ }^{[24]}$ However, the interstitial oxide ion mobility in aluminate melilites is much lower than that in gallate melilites (Figure 10c), e.g. in the $600-800^{\circ} \mathrm{C}$ range, the conductivity of $\mathrm{La}_{1.5} \mathrm{Ca}_{0.5} \mathrm{Al}_{3} \mathrm{O}_{7.25}$ varied within $-10^{-4}-10^{-3} \mathrm{~S} / \mathrm{cm}$, which is lower than that of $\mathrm{La}_{1.2} \mathrm{Sr}_{0.8} \mathrm{Ga}_{3} \mathrm{O}_{7.1} \quad\left(-10^{-3}-10^{-2} \mathrm{~S} / \mathrm{cm}\right)$ although containing smaller interstitial oxide ion content than $\mathrm{La}_{1.5} \mathrm{Ca}_{0.5} \mathrm{Al}_{3} \mathrm{O}_{7.25}$. Aluminate melilite oxide ion conductors also showed decomposition at temperature above $700{ }^{\circ} \mathrm{C}{ }^{[24]}$

\section{Thermal and Chemical Stability}

Although $\mathrm{La}_{1+x} \mathrm{Sr}_{1-x} \mathrm{Ga}_{3} \mathrm{O}_{7+0.5 x}$ gallate melilite oxide ion conductors can be sintered at high temperatures $\left(\geq 1300^{\circ} \mathrm{C}\right)$ in the traditional ceramic route, the La-rich compounds still suffer from decomposition, which should be taken into consideration when used as electrolyte for SOFCs. Regarding the as-prepared $\mathrm{La}_{1.54} \mathrm{Sr}_{0.46} \mathrm{Ga}_{3} \mathrm{O}_{7.27}$ composition, our examination indicated that it remained stable on heating up to $800^{\circ} \mathrm{C}$ and then went through a metastable range from $800^{\circ} \mathrm{C}$ to $1200^{\circ} \mathrm{C}$, showing decomposition into Sr-doped $\mathrm{LaGaO}_{3}$ perovskite and $\mathrm{Ga}_{2} \mathrm{O}_{3}$ phases, which reacted with each other to reform single melilite phase. ${ }^{[20]}$ Therefore any thermal process post electrolyte sintering for SOFC application should avoid 
this metastable temperature range. Similar decomposition was also observed in metastable oxide ion conducting melilite phases synthesized from the glass crystallisation routes. ${ }^{[22,24]} \mathrm{On}$ the other hand, chemical compatibility with electrode materials is also of great importance for SOFC application. According to Mancini et al. ${ }^{[41]}$, the $\mathrm{La}_{1.5} \mathrm{Sr}_{0.5} \mathrm{Ga}_{3} \mathrm{O}_{7.25}$ melilite electrolyte is not compatible with $\mathrm{La}_{2} \mathrm{NiO}_{4+\mathrm{d}}$ or $\mathrm{La}_{0.8} \mathrm{Sr}_{0.2} \mathrm{MnO}_{3-\mathrm{d}}$ but gets along with $\mathrm{La}_{0.8} \mathrm{Sr}_{0.2} \mathrm{Fe}_{0.8} \mathrm{Cu}_{0.2} \mathrm{O}_{3-\mathrm{d}}$. Therefore the $\mathrm{La}_{1+x} \mathrm{Sr}_{1-}$ ${ }_{x} \mathrm{Ga}_{3} \mathrm{O}_{7+0.5 x}$ melilite possesses potential application as an electrolyte in SOFCs and other related devices within intermediate temperature range.

\section{Oxygen Vacancy Conduction}

In addition to interstitial oxygen defects, the melilite structure can also accommodate oxygen vacancy defects. For example, in $\mathrm{LaSrGa}_{3} \mathrm{O}_{7}$-based materials, Sr can replace $\mathrm{La}$, such forming a solid solution $\mathrm{La}_{1-x} \mathrm{Sr}_{1+x} \mathrm{Ga}_{3} \mathrm{O}_{7-0.5 x}(x \leq 0.2)$ containing oxygen vacancies, which was confirmed by the Rietveld structure analysis of $\mathrm{La}_{0.8} \mathrm{Sr}_{1.2} \mathrm{Ga}_{3} \mathrm{O}_{6.9}$ on $\mathrm{NPD}$ data. ${ }^{[42]}$ The oxygendeficient $\mathrm{La}_{0.8} \mathrm{Sr}_{1.2} \mathrm{Ga}_{3} \mathrm{O}_{6.9}$ shows limited ionic conduction ( $10^{-4}-10^{-6} \mathrm{~S} / \mathrm{cm}$ over the $800-1000^{\circ} \mathrm{C}$ temperature range), which is -2 orders of magnitude higher than the parent material $\mathrm{LaSrGa}_{3} \mathrm{O}_{7}$ but $-3-4$ orders of magnitude lower than the interstitial oxide ion conductivity in La-rich component $\mathrm{La}_{1.54} \mathrm{Sr}_{0.46} \mathrm{Ga}_{3} \mathrm{O}_{7.27}$. Schuett et al. conducted a detailed investigation of the migration energies of oxygen vacancy defects in the composition $\mathrm{La}_{0.5} \mathrm{Sr}_{1.5} \mathrm{Ga}_{3} \mathrm{O}_{6.7}$ by DFT and $\mathrm{KMC}$ simulations. ${ }^{[26]}$ The results showed that the oxygen vacancies at different positions in $\mathrm{La}_{0.5} \mathrm{Sr}_{1.5} \mathrm{Ga}_{3} \mathrm{O}_{6.7}$ have different formation energies in an order of $\mathrm{O} 3<\mathrm{O} 2<\mathrm{O} 1$ and the favorable migration path of oxide ions in the oxygen-deficient composition is composed of jumps among $\mathrm{O} 3$ sites linking $\mathrm{Ga} 1$ and $\mathrm{Ga} 2$. The calculated migration barriers of oxygen vacancies 0.64-0.72 eV. In 2014 Tealdi et al. reported $\mathrm{Na}$-doped $\mathrm{Sr}_{2} \mathrm{MgSi}_{2} \mathrm{O}_{7}$ showing high oxide ion conductivity: at $700^{\circ} \mathrm{C}$, the conductivity of $\mathrm{Sr}_{1.6} \mathrm{Na}_{0.4} \mathrm{MgSi}_{2} \mathrm{O}_{6.8}$ reached $-6 \times 10^{-3} \mathrm{~S} /$ $\mathrm{cm}$, which is about 6 orders of magnitude higher than that of undoped $\mathrm{Sr}_{2} \mathrm{MgSi}_{2} \mathrm{O}_{7} \cdot{ }^{[43]}$ They stipulated that the replacement of $\mathrm{Sr}$ by $\mathrm{Na}$ ions induces oxygen vacancies, which are charge carriers for the ionic conduction.

Generally, oxygen vacancies in tetrahedra can be stabilized by sharing vertex oxygen with adjacent tetrahedra. ${ }^{[44]}$ However, at present, we still do not have a clear understanding of whether the local structure relaxes around the oxygen vacancies to avoid the occurrence of unstable 3-coordinated structural units in the melilite structure. Given that the real charge carriers have been corrected as $\mathrm{Na}^{+}$or $\mathrm{K}^{+}$in $\mathrm{Na} / \mathrm{K}$-doped $\mathrm{SrSiO}_{3}$ by many research groups all over the world, ${ }^{[45-47]}$ although it was initially reported as oxide ion conductors, ${ }^{[48-50]}$ we would like to emphasize that it is difficult to create oxygen vacancies in linked tetrahedral networks. Even in isolated tetrahedral anion structures, oxygen vacancy-mediated oxide ion conductors are very few. ${ }^{[51,52]}$ In 2017, Collins et al. reported A-cation excess melilite structure on $\mathrm{SrCa}_{1.5} \mathrm{Ga}_{3} \mathrm{O}_{7}$ based compositions. ${ }^{[53]}$ Therefore, the possibility that two $\mathrm{La}^{3+}$ in the melilite structure are replaced by three $\mathrm{Sr}^{2+}$ to form a solid solution of $\mathrm{La}_{1-2 / 3 x} \mathrm{Sr}_{1+x} \mathrm{Ga}_{3} \mathrm{O}_{7}$ can not completely excluded for the nominal oxygen-deficient compositions $\mathrm{La}_{1-}$ ${ }_{x} \mathrm{Sr}_{1+x} \mathrm{Ga}_{3} \mathrm{O}_{7-0.5 x}$. In other word, it would be also possible that there are excessive $\mathrm{Sr}^{2+}$ cations in the cation layer instead of oxygen vacancies. Therefore, whether charge carriers are oxide ions in the acceptor doped gallate and silicate melilites and the introduction of oxygen vacancies is an effective way to design materials with high oxide ion conductivity in melilite structures still remain as open questions.

\section{Conclusion and Future Outlook}

The discovery of interstitial oxide ion conduction in melilites opened up a new approach of tetrahedra-based structure chemistry for the search and design of new interstitial oxide ion conductors. During the past twelve years, we have been accumulating more and more in-depth understanding of interstitial oxide ion stabilization and migration mechanisms in melilites from the following experimental and theoretical aspects.

(1) In gallate melilite oxide ion conductors based on trivalent rare earth elements substitution for divalent alkaline earth metal cations, the interstitial oxide ion enters a site close to the pentagonal ring center. It forms bonds with one threelinked tetrahedral $\mathrm{Ga}$ center and migrates among the pentagonal rings within the tetrahedral layers through a synergic knock-on mechanism with the framework oxygen atoms. The open pentagonal ring with the void size matching the interstitial oxide ion, the variable coordination number of $\mathrm{Ga}^{3+}$ cations, and the rotation and deformation flexibility of the 2-dimensional $(3,4)$-connected tetrahedral network $\mathrm{Ga}_{3} \mathrm{O}_{7}$ layer with terminal oxygen are the key factors for the accommodation and transport of the interstitial oxide ions in the melilite structure. Interstitial oxide ion ordering takes place among the pentagonal rings along both the diagonal axes of the $a b$ plane and $c$ axis of the tetragonal cell at high interstitial oxide ion contents, which reduces the structural symmetry and interstitial oxide ion mobility. The structural relaxation around oxygen interstitial defects allows for a theoretically maximum loading of oxygen interstitials, $25 \%$ in the pentagonal rings. The interstitial oxide ion in melilite can be also introduced through oxidation, under which the interstitial oxide ion locates at the framework oxygen level, placing significant constrains to the migration of interstitial oxide ions and 
demonstrating the diversity of interstitial oxide ion stabilization mechanisms in melilite structures.

(2) The incorporation of interstitial oxygen into the fivemember ring makes the pentagonal rings to expand and shrink cooperatively. Therefore, in order to obtain a certain content of interstitial oxygens and maintain their high mobility, the size of A cations in the pentagonal channel should not be too large or too small. In addition to this ionic size effect, the chemical bonding effect also takes place on the stabilization and migration of interstitial oxygens in melilites. Large electropositive A cations in the pentagonal channels and Ga cations in the tetrahedral layers interact with the interstitial oxide ions through ionic and covalent bonding respectively to stabilize the interstitial oxygen. The weak antibonding interaction between framework and interstitial oxygen atoms promotes covalent bonding between interstitial oxygens and Ga ions, and makes interstitial and framework oxygens highly active, thus facilitating the migration of these interstitial oxygens. When $\mathrm{Pb}^{2+}$ ions, with covalent bonding characteristic, are placed in the pentagonal channels, the asymmetric distribution of lone pair electrons streaming into the pentagonal ring inhibits the incorporation of interstitial oxygen into the pentagonal ring.

(3) Metastable aluminate and gallate melilite oxide ion conductors containing rare earth elements smaller than La, which cannot be prepared by traditional solid state reaction, can be prepared using a glass crystallization route using an aerodynamic levitation coupled to laser heating system. The interstitial oxide ions in the aluminate melilites have much lower mobility compared with those in the gallate melilite counterparts. Fully dense transparent ceramics were obtained for $\mathrm{Eu}, \mathrm{Gd}$ and Tb-containing gallate melilites, which showed high bulk conductivity $\sim 0.01 \mathrm{~S} / \mathrm{cm}$ at $470^{\circ} \mathrm{C}$. However, these aluminate and gallate melilite oxide ion conductors, and even the $\mathrm{La}_{1+x} \mathrm{Sr}_{1-x} \mathrm{Ga}_{3} \mathrm{O}_{7+0.5 x}$ with the best performance, suffer from metastability showing decomposition at high temperatures above 700 or $800^{\circ} \mathrm{C}$. This decomposition is showing up at the grain boundary level, which become highly insulating in the transparent gallate melilite oxide ion conductors synthesized from the glass crystallizaiton route.

The above research progress on the stabilization and migration mechanisms of interstitial oxygen defects in melilite structures provides new ideas on structural design and preparation of the next-generation oxide ion conductors based on tetrahedral structural units. There could be large possibility to access new compositions of melilites through the soft chemistry process e.g. the glass-ceramic route. It is interesting to note here that some borates can form melilite structures under high pressure. ${ }^{[54]}$ Therefore high temperature and high pressure reaction could be also an interesting method for discovery of new melilites. These nontraditinal synthetic routes may offer great chance for identifing the new oxide ion conductors and enhancing the conductivity. In the future, understanding of the oxide ion migration dynamics at high temperature in melilites could be further enhanced through using local structure sensitive solid-state NMR technique e.g. VT ${ }^{69 / 71} \mathrm{Ga}$ or ${ }^{17} \mathrm{O}$ NMR. The vacancy conduction, which remains an open question in gallate and silicate melilites, requires further investigation in order to fully understand the local structural relaxation and explore the advantages of melilite structures on transporting oxide ions. From a practical application point of view, SOFCs with $\mathrm{LaSrGa}_{3} \mathrm{O}_{7}$-based melilite electrolytes that can be assembled with electrodes at low temperature could be also interesting for exploitation. Finally, the diversity of defect structures around the interstitial oxygen atoms observed in the melilite structure shows that the melilite structure has great flexibility, which provides interesting host materials for defect engineering aiming for novel local structures and properties.

\section{Acknowledgements}

National Natural Science Foundation of China (No. 21622101), Guangxi Natural Science Foundation (No. 2019GXNSFGA245006), Guangxi University Hundred Talent Program for Returned Oversea Scholars are acknowledged for the financial support.

\section{References}

[1] R. Caracas, X. Gonze, Phys. Rev. B. 2003, 68, 184102.

[2] L. Peters, K. Knorr, M. Knapp, W. Depmeier, Phys. Chem. Miner. 2005, 32, 546-551.

[3] K. Q. Huang, R. S. Tichy, J. B. Goodenough, J. Am. Ceram. Soc. 1998, 81, 2565-2575.

[4] M. Steins, W. Schmitz, R. Uecker, J. Doerschel, Z. Kristallogr. New Cryst. Struct. 1997, 212, 76.

[5] P. J. Majewski, R. Michael, S. Heike, A. Fritz, J. Am. Ceram. Soc. 2001, 84, 1093-1096.

[6] M. Rozumek, P. Majewski, L. Sauter, F. Aldinger, J. Am. Ceram. Soc. 2004, 87, 662-669.

[7] M. Rozumek, P. Majewski, H. Schluckwerder, F. Aldinger, K. Künstler, G. Tomandl, J. Am. Ceram. Soc. 2004, 87, 17981798.

[8] E. S. Raj, S. J. Skinner, J. A. Kilner, Solid State Ionics. 2005, 176, 1097-1101.

[9] X. J. Kuang, M. A. Green, H. J. Niu, P. Zajdel, C. Dickinson, J. B. Claridge, L. Jantsky, M. J. Rosseinsky, Nat. Mater. 2008, 7, 498-504.

[10] S. Nakayama, T. Kageyama, H. Aono, Y. Sadaoka, J. Mater. Chem. 1995, 5, 1801-1805.

[11] L. León-Reina, E. R. Losilla, M. Martínez-Lara, S. Bruque, M. A. Aranda, J. Mater. Chem. 2004, 14, 1142-1149. 
[12] M. S. Islam, J. R. Tolchard, P. R. Slater, Chem. Commun. 2003, 1486-1487.

[13] L. León-Reina, E. R. Losilla, M. Martínez-Lara, M. C. MartínSedeño, S. Bruque, P. Núnez, D. V. Sheptyakov, M. A. Aranda, Chem. Mater. 2005, 17, 596-600.

[14] M. Lacerda, J. T. S. Irvine, F. P. Glasser, A. R. West, Nature. 1988, 332, 525-526.

[15] H. B. Yi, Y. Lv, Y. H. Wang, X. Fang, V. Mattick, J. Xu, RSC Adv. 2019, 9, 3809-3815.

[16] O. Yamamoto, Y. Arati, Y. Takeda, N. Imanishi, Y. Mizutani, M. Kawai, Y. Nakamura, Solid State Ionics. 1995, 79, 137-142.

[17] J. G. Cheng, S. W. Zha, J. Huang, X. Q. Liu, G. Y. Meng, Mater. Chem. Phys. 2003, 78, 791-795.

[18] F. Wei, T. Baikie, T. An, M. Schreyer, C. Kloc, T. J. White, J. Am. Chem. Soc. 2011, 133, 15200-15211.

[19] C. Tealdi, P. Mustarelli, M. S. Islam, Adv. Funct. Mater. 2010, 20, 3874-3880.

[20] C. I. Thomas, X. Kuang, Z. Deng, H. Niu, J. B. Claridge, M. J. Rosseinsky, Chem. Mater. 2010, 22, 2510-2516.

[21] H. J. Park, T.-G. Kim, C. Kwak, D. W. Jung, S. Lee, K. H. Lee, J. Power Sources. 2015, 275, 884-887.

[22] M. Boyer, X. Y. Yang, A. J. F. Carrion, Q. C. Wang, E. Veron, C. Genevois, L. Hennet, G. Matzen, E. Suard, D. Thiaudiere, C. Castro, D. Pelloquin, L. B. Kong, X. J. Kuang, M. Allix, J. Mater. Chem. A. 2018, 6, 5276-5289.

[23] A. Mancini, C. Tealdi, L. Malavasi, Int. J. Hydrogen Energy. 2012, 37, 8073-8080.

[24] J. G. Xu, J. H. Wang, A. Rakhmatullin, S. Ory, A. J. Fernandez-Carrion, H. B. Yi, X. J. Kuang, M. Allix, Acs Appl. Energy Mater. 2019, 2, 2878-2888.

[25] J. G. Xu, Y. C. Li, L. J. Zhou, X. Tang, X. J. Kuang, Adv. Theor. Simul. 2019, 2, 1900069.

[26] J. Schuett, T. K. Schultze, S. Grieshammer, Chem. Mater. 2020, 32, 4442-4450.

[27] J. G. Xu, X. J. Kuang, E. Véron, M. Allix, M. R. Suchomel, F. Porcher, C. L. Liang, F. J. Pan, M. M. Wu, Inorg. Chem. 2014, 53, 11589-11597.

[28] T. G. Kim, S. J. Kim, C. C. Lin, R. S. Liu, T. S. Chan, S. J. Im, J. Mater. Chem. C. 2013, 1, 5843-5848.

[29] F. X. Wei, H. Gasparyan, P. J. Keenan, M. Gutmann, Y. Fang, T. Baikie, J. B. Claridge, P. R. Slater, C. L. Kloc, T. J. White, J. Mater. Chem. A. 2015, 3, 3091-3096.

[30] B. B. Liu, D. Dong, Z. B. Liu, F. L. Chen, C. R. Xia, Solid State Ionics. 2011, 191, 68-72.

[31] J. H. Wang, Y. H. Wang, L. J. Zhou, Guangdong Chem. Ind.. 2018, 14, 3-6.

[32] J. G. Xu, J. H. Wang, X. Tang, X. J. Kuang, M. J. Rosseinsky, Inorg. Chem. 2017, 56, 6897-6905.

[33] M. R. Li, X. J. Kuang, S. Y. Chong, Z. L. Xu, C. I. Thomas, H. Niu, J. B. Claridge, M. J. Rosseinsky, Angew. Chem. Int. Ed. Engl. 2010, 49, 2362-2366.

[34] M. Allix, S. Alahrache, F. Fayon, M. Suchomel, F. Porcher, T. Cardinal, G. Matzen, Adv. Mater. 2012, 24, 5570-5575.

[35] S. Alahrache, K. Al Saghir, S. Chenu, E. Veron, D. D. Meneses, A. I. Becerro, M. Ocana, F. Moretti, G. Patton, C. Dujardin, F.
Cusso, J. P. Guin, M. Nivard, J. C. Sangleboeuf, G. Matzen, M. Allix, Chem. Mater. 2013, 25, 4017-4024.

[36] K. Al Saghir, S. Chenu, E. Veron, F. Fayon, M. Suchomel, C. Genevois, F. Porcher, G. Matzen, D. Massiot, M. Allix, Chem. Mater. 2015, 27, 508-514.

[37] M. Boyer, S. Alahrache, C. Genevois, M. Licheron, F. X. Lefevre, C. Castro, G. Bonnefont, G. Patton, F. Moretti, C. Dujardin, G. Matzen, M. Allix, Cryst. Growth Des. 2016, 16, 386-395.

[38] M. Boyer, A. J. F. Carrion, S. Ory, A. I. Becerro, S. Villette, S. V. Eliseeva, S. Petoud, P. Aballea, G. Matzen, M. Allix, J. Mater. Chem. C. 2016, 4, 3238-3247.

[39] A. Bertrand, J. Carreaud, S. Chenu, M. Allix, E. Veron, J. R. Duclere, Y. Launay, T. Hayakawa, C. Genevois, F. Brisset, F. Celarie, P. Thomas, G. Delaizir, Adv. Opt. Mater. 2016, 4, $1482-1486$.

[40] X. G. Ma, X. Y. Li, J. Q. Li, C. Genevois, B. Q. Ma, A. Etienne, C. L. Wan, E. Veron, Z. J. Peng, M. Allix, Nat. Commun. 2018, 9, 1-9.

[41] A. Mancini, V. Felice, I. N. Sora, L. Malavasi, C. Tealdi, J. Solid State Chem. 2014, 213, 287-292.

[42] J. G. Xu, X. H. Li, F. Q. Lu, H. Fu, C. M. Brown, X. J. Kuang, J. Solid State Chem. 2015, 230, 309-317.

[43] C. Tealdi, G. Chiodelli, S. Pin, L. Malavasi, G. Flor, J. Mater. Chem. A. 2014, 2, 907-910.

[44] E. Kendrick, J. Kendrick, K. S. Knight, M. S. Islam, P. R. Slater, Nat. Mater. 2007, 6, 871-875.

[45] R. D. Bayliss, S. N. Cook, D. O. Scanlon, S. Fearn, J. Cabana, C. Greaves, J. A. Kilner, S. J. Skinner, J. Mater. Chem. A. 2014, 2, 17919-17924.

[46] I. R. Evans, J. S. Evans, H. G. Davies, A. R. Haworth, M. L. Tate, Chem. Mater. 2014, 26, 5187-5189.

[47] J. G. Xu, S. B. Liu, Q. C. Wang, J. S. Xiaofeng, X. H. Li, X. J. Kuang, J. Mater. Chem. A. 2016, 4, 6313-6318.

[48] P. Singh, J. B. Goodenough, Energy Environ. Sci. 2012, 5, 9626-9631.

[49] P. Singh, J. B. Goodenough, J. Am. Chem. Soc. 2013, 135, 10149-10154.

[50] J. G. Xu, X. M. Wang, H. Fu, C. M. Brown, X. P. Jing, F. H. Liao, F. Q. Lu, X. H. Li, X. J. Kuang, M. M. Wu, Inorg. Chem. 2014, 53, 6962-6968.

[51] X. Y. Yang, A. J. Fernandez-Carrion, J. H. Wang, F. Porcher, F. Fayon, M. Allix, X. J. Kuang, Nat. Commun. 2018, 9, 1-11.

[52] S. Li, F. Schönberger, P. Slater, Chem. Commun. 2003, 26942695.

[53] C. Collins, M. S. Dyer, M. J. Pitcher, G. F. S. Whitehead, M. Zanella, P. Mandal, J. B. Claridge, G. R. Darling, M. J. Rosseinsky, Nature. 2017, 546, 280-284.

[54] M. K. Schmitt, K. Ploner, C. Hejny, H. Huppertz, Z. Anorg. Allg. Chem. 2017, 643, 1844-1848.

\footnotetext{
Manuscript received: June 8, 2020

Revised manuscript received: July 5, 2020

Version of record online:
} 